\title{
Radiographic evaluation of furcal perforations sealed with different materials in dogs' teeth
}

\author{
José Roberto VANNI', Álvaro DELLA-BONA², José Antônio Poli de FIGUEIREDO³, Giovani PEDRO4, Douglas VOSS ${ }^{4}$, \\ Patrícia Maria Poli KOPPER \\ 1- DDS, MSc, PhD; Coordinator of the Endodontic Integrated Center, Passo Fundo, RS, Brazil. \\ 2- DDS, MSc, PhD; Senior Professor of Dental Biomaterials, Dental School, University of Passo Fundo, Passo Fundo, RS, Brazil. \\ 3- DDS, MSc, PhD; Senior Lecturer in Endodontology, Dean of the Graduate Program in Dentistry, Dental School, Pontifical Catholic University of Rio Grande \\ do Sul, Porto Alegre, RS, Brazil. \\ 4- DDS, University of Passo Fundo, Passo Fundo, RS, Brazil. \\ 5- DDS, MSc, PhD; Senior Lecturer in Endodontology, Dental School, Federal University of Rio Grande do Sul, Porto Alegre, RS, Brazil.
}

Corresponding address: Patrícia Maria Poli Kopper. - Rua Ramiro Barcelos, 2492 - Porto Alegre, RS - Brasil - e-mail: pkopper@terra.com.br

Received: July 10, 2009 - Modification: August 26, 2010 - Accepted: October 26, 2010

\section{ABSTRACT}

\begin{abstract}
$\mathrm{O}$ bjective: The objective of this work was to evaluate, using radiographic images, the behavior of four materials used to repair root perforations in dogs' teeth. Material and Methods: Second and third premolars of 6 dogs were used. The 48 teeth were randomly divided into 4 groups $(n=12)$ and the perforations were sealed with one of the following materials: MTA, AH Plus, Vitremer and gutta-percha. Dogs were submitted to general anesthesia, teeth were radiographed and pulp was accessed. Perforations were done, at the maximum curve of the pulp floor, sealed and the accessed coronal cavity was filled with glass ionomer cement (Vidrion R). After 90 days, the dogs were sacrificed and the last $x$-ray image was taken. Images were analyzed for the presence/absence of periodontal lesions at the perforation region. Data were analyzed statistically by chi-square test at $5 \%$ significance level. Results: There were no statistically significant differences $(p \geq 0.05)$ among AH Plus, Vitremer and gutta-percha groups. MTA produced the smallest number of periodontal lesions $(p<0.05)$. Conclusions: It may be concluded that none of the tested materials was able to preserve the integrity of the periodontal tissues in the furcation region, and the use of MTA resulted in the least formation of adjacent periodontal bone lesions revealed by the radiographic comparisons.
\end{abstract}

Key words: Iatrogenic disease. Dental radiography. Furcation defects. Materials.

\section{INTRODUCTION}

Iatrogenic root perforation is an endodontic procedural accident in which an artificial opening is created during tooth preparation causing a communication between the pulp space and the surrounding periodontal tissues ${ }^{19}$.

Perforations in the furcation region have been considered one of the major complications leading to failure of endodontic treatment and they might result from the use of a misdirected drill while gaining access to the root canals ${ }^{2}$. Furcal perforations have a more unfavorable prognosis than the perforations occurring in the middle and apical root third. Factors such as the time elapsed between the accident and the obturation of the perforation as well as the quality of the restoration placed to seal the coronal access cavity considerably interfere with treatment success ${ }^{8}$.

Furcal perforations might be sealed either intracoronally or with external surgical access. The nonsurgical intracoronal intervention usually precedes the surgical repair of root perforations. In both approaches, a good sealing must be obtained between tooth structure and the periodontium, which might be affected by the size and location of the perforation, operative technique and physicochemical characteristics of the material used to close the communication ${ }^{12}$.

Ideally, the material used for sealing of root perforations should be atoxic, non-resorbable, radiopaque and bacteriostatic and should have 
good sealability ${ }^{13}$. In addition, the material should present an osteogenic inductive capacity and biocompatibility ${ }^{17}$. Taking into account these characteristics and prerequisites, the use and/or behavior of different materials for sealing of root perforations has been investigated ${ }^{7,10}$.

A mineral trioxide aggregate (MTA) has been developed at Loma Linda University (USA) with the specific goal of sealing communications between the tooth and the external surfaces. This material has been described as a powder composed of minuscule hydrophilic particles that sets in contact with humidity. Powder hydration produces a colloidal gel with $\mathrm{pH}$ around 12.5 , which solidifies into a rigid structure within approximately $4 \mathrm{~h}$. MTA is slightly more radiopaque than dentin, has low solubility and its compressive strength twentyone days after setting is $70 \mathrm{MPa}$, which allows restorative materials to be condensed over a MTA base without affecting its structure ${ }^{15,18}$.

This study investigated the hypothesis that MTA is more effective to prevent the formation of periodontal bone lesions adjacent to root perforations than AH Plus endodontic sealer, Vitremer resin-modified glass ionomer cement and gutta-percha. For such purpose, the behavior of these four materials used for sealing of perforations in dogs' teeth was assessed on the basis of a radiographic evaluation within a 90 -day period.

\section{MATERIAL AND METHODS}

This research project was approved by the Ethics in Research Committee of the University of Passo Fundo (CEP No. 437/2004). The experimental phase and the analysis of the results were performed at the University of Passo Fundo (UPF).

Six 2-3 year-old mongrel dogs weighing 10$15 \mathrm{~kg}$ were selected. Throughout the study, the animals were examined, treated and fed by a designated veterinary from UPF. The maxillary and mandibular second and third premolars of both sides were used in the study, making a total of 48 teeth ( 8 teeth per dog).

All procedures were carried out under general anesthesia. The animals were anesthetized intramuscularly with a combination of ketamine hydrochloride (Francotar; Virbac do Brasil Indústria e Comércio Ltda., Roseira, SP, Brazil; $15 \mathrm{~mL} / \mathrm{kg}$ body weight), xylazine hydrochloride (Virbaxyl $2 \%$; Virbac do Brasil Indústria e Comércio Ltda; $1 \mathrm{~mL} / \mathrm{kg}$ body weight) and atropine sulfate (Atropina 1\% Fraga; Farmagrícola S.A. Importação e Exportação, Mairiporã, SP, Brazil; $0.044 \mathrm{~mL} / \mathrm{kg}$ body weight). Thereafter, the dogs were given saline intravenously (Laboratório JP Indústria Farmacêutica S.A., Ribeirão Preto, SP, Brazil) and were intubated to receive $100 \%$ oxygen. Saline and $100 \%$ oxygen were administered throughout the procedure. Anesthesia was maintained by intravenous injection of $5 \mathrm{~mL} / \mathrm{kg}$ of ketamine and $0.33 \mathrm{~mL} / \mathrm{kg}$ of xylazine hydrochloride at $30-\mathrm{min}$ intervals ${ }^{11}$.

Before the clinical procedures, antisepsis of the soft tissues and teeth was performed with gauze soaked in iodinated alcohol (Farmácia Escola ULBRA, Canoas, RS, Brazil). Then, periapical radiographs of the teeth were taken. The film holder (Angelus, Londrina, PR, Brazil) securing the radiographic film (Kodak Ultra-Speed; Eastman Kodak Company, New York, NY, USA) was taken to the dog's mouth. After correct positioning of the cylinder, the $\mathrm{x}$-ray equipment (Time X66; Gnatus Equipamentos Médico-Odontológicos Ltda, Ribeirão Preto, SP, Brazil) was started with $0.5 \mathrm{~s}$ exposure time. The radiographs were processed in an automatic processor (GXP ${ }^{\circledR}$, Gendex Dental Systems, Des Plaines, IL, USA) and analyzed. Only the teeth with integrity of periodontal tissues were included in the study.

To access the root canals, a coronal opening was performed on the occlusal surface of the teeth using a \#1014 round diamond bur (Metalúrgica Fava Indústria e Comércio Ltda., Francisco da Rocha, SP, Brazil) at high-speed and under constant saline cooling. After complete removal of the pulp chamber roof, coronal pulp tissue was extirpated using a \#17 curette (Duflex; SS White Artigos Dentários Ltda., Rio de Janeiro, RJ, Brazil).

For preparation of each experimental root perforation, a LN bur (Dentsply Maillefer, Ballaigues, Switzerland) coupled to a low-speed handpiece was positioned perpendicular to the maximum concavity of the pulp chamber floor and was driven in a cervico-apical direction until the periodontal tissues were reached. The access cavity and the root perforation were irrigated with saline, simultaneously aspirated with a \#20 aspiration canulla (Becton Dickinson Indústrias Cirúrgicas Ltda, Juiz de Fora, MG, Brazil), and dried with sterile cotton pellets until complete hemostasis was obtained. Calcium hydroxide powder was delivered to the pulp chamber of all teeth using a small, sterile endodontic plunger (Duflex; SS White Artigos Dentários Ltda.) and was gently accommodated over the root pulp remnant.

The experimentally produced root perforations were sealed with the following materials (12 teeth per material): MTA - mineral trioxide aggregate (ProRoot ${ }^{T M}$ MTA; Dentsply Tulsa Denal, Tulsa, OK, USA); AH - AH Plus resin-based endodontic sealer (Dentsply DeTrey GmbH, Konstanz, Germany); GIC - Vitremer resin-modified glass ionomer cement (3M ESPE, St. Paul, MN, USA); and GP (control) gutta-percha (Dentsply Indústria e Comércio Ltda, Petrópolis, RJ, Brazil). 
A stratified randomization was performed to determine the material to be used in each tooth. Six charts (one per unidentified dog) containing the material to be employed in each tooth were set before carrying out experimental procedures. Care was taken to warrant that all dogs had two teeth sealed with each of tested materials. Once the pulp capping procedures were completed, a chart was randomly assigned to each dog. This random assignment was followed until there was only one chart, which was assigned to the last dog submitted to treatment.

MTA, AH and GIC were handled and mixed according to the manufacturers' instructions, and were taken to the perforations using an instrument specific for placement of calcium hydroxidebased cements ( $\mathrm{CAH}$, Duflex, Rio de Janeiro, by the chi-square nonparametric test at $5 \%$ significance level.

\section{RESULTS}

Table 1 and Figure 1 show the radiographic findings regarding the presence or absence of radiolucent areas (lesions) in the furcation region of the dogs' teeth with root perforations sealed with MTA, AH, GIC and GP after 90 days. In $58.3 \%$ of the cases sealed with MTA, no furcation lesions were observed within the evaluated period. Likewise, no furcation lesions developed in $25 \%$ and $8.3 \%$ of the cases sealed with GIC and AH, respectively. On the other hand, furcation bone lesions were observed in $100 \%$ of the cases that perforations were sealed with GP.

Table 1- Absolute and relative frequency of presence or absence of radiolucent areas (lesions) in the furcation region of the dogs' teeth with root perforations sealed by mineral trioxide aggregate (MTA), $\mathrm{AH}$ Plus $(\mathrm{AH})$, Vitremer resin-modified glass ionomer cement (GIC) and gutta-percha (GP) after 90 days

\begin{tabular}{lcccc}
\hline & $\begin{array}{c}\text { MTA } \\
\mathbf{n}=\mathbf{1 2 ( 1 0 0 \% )}\end{array}$ & $\begin{array}{c}\text { GIC } \\
\mathbf{n}=\mathbf{1 2}(\mathbf{1 0 0} \%)\end{array}$ & $\begin{array}{c}\text { AH } \\
\mathbf{n}=\mathbf{1 2}(\mathbf{1 0 0} \%)\end{array}$ & $\begin{array}{c}\text { GP } \\
\mathbf{n}=\mathbf{1 2}(\mathbf{1 0 0} \%)\end{array}$ \\
\hline Presence & $5(41.7 \%)$ & $9(75.0 \%)$ & $11(91.7 \%)$ & $12(100 \%)$ \\
Absence & $7(58.3 \%)$ & $3(25.0 \%)$ & $1(8.3 \%)$ & $0(0 \%)$ \\
\hline
\end{tabular}

RJ, Brazil). The experimentally produced root perforations were filled without excess and using gentle pressure. Gutta-percha was warmed over an alcohol flame and the plasticized material was taken to the perforations using a plunger.

Once all perforations had been sealed, the access cavities were filled with conventional glassionomer cement (Vidrion R; SS White Artigos Dentários Ltda.) using a Centrix injector (DFL, Rio de Janeiro, RJ, Brazil) and the teeth were radiographed again.

Ninety days after the procedures, the animals were euthanized by an overdose of $3 \%$ sodium pentobarbital (Hypnol; Cristalia, Produtos Químicos e Farmacêuticos Ltda., Itatiba, SP, Brazil). These dogs were killed because they were experimental animals of other surgical procedures conducted by medical students from the University of Passo Fundo.

New radiographs were taken of the teeth under study in the same manner as previously described. The developed radiographs were analyzed and compared to those taken before the perforations. A single examiner blinded to the groups and to study methodology analyzed the radiographic images with respect to the presence or absence of radiolucencies in the furcation region that would be suggestive of the presence or absence of periodontal lesions. Data were analyzed statistically

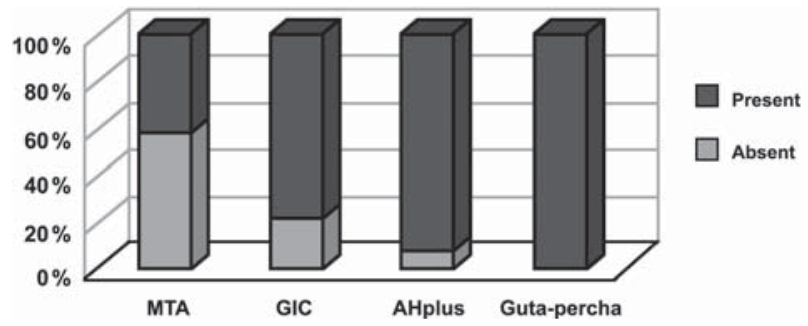

Figure 1-Percentage of presence/absence of periodontal lesions in the teeth with perforations sealed with MTA, AH Plus (endodontic sealer), Vitremer (GIC - glass ionomer cement) and gutta-percha

Statistical analysis by chi-square showed no statistically significant difference among the groups sealed with $A H$, GIC and GP ( $p>0.05)$. In contrast, the group sealed with MTA showed the least incidence of lesion formation in the furcation region and differed statistically from the other groups $(p<0.05)$.

Figure 2 shows a radiographic image with absence of periodontal bone lesion in the furcation region, while Figure 3 shows a radiographic image with presence of a radiolucent area in the furcation region, suggestive of a periodontal bone lesion. 


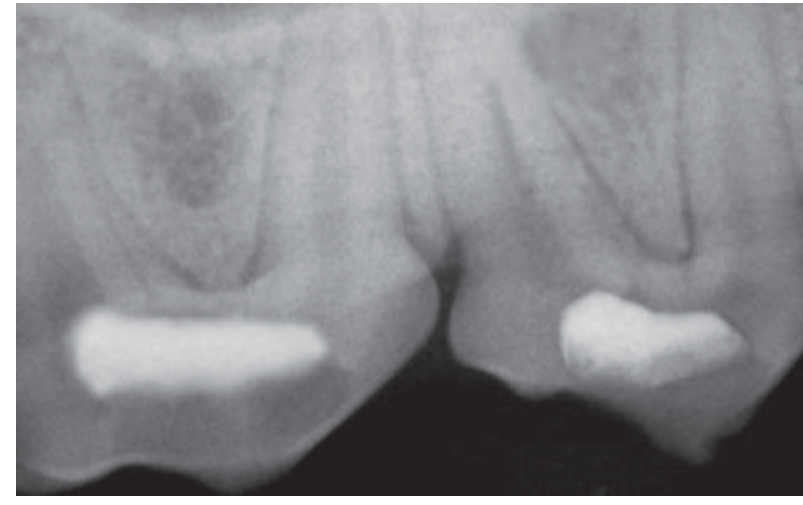

Figure 2- Periapical radiograph of the right maxillary second and third premolars sealed with MTA showing absence of periodontal lesion in the perforation region

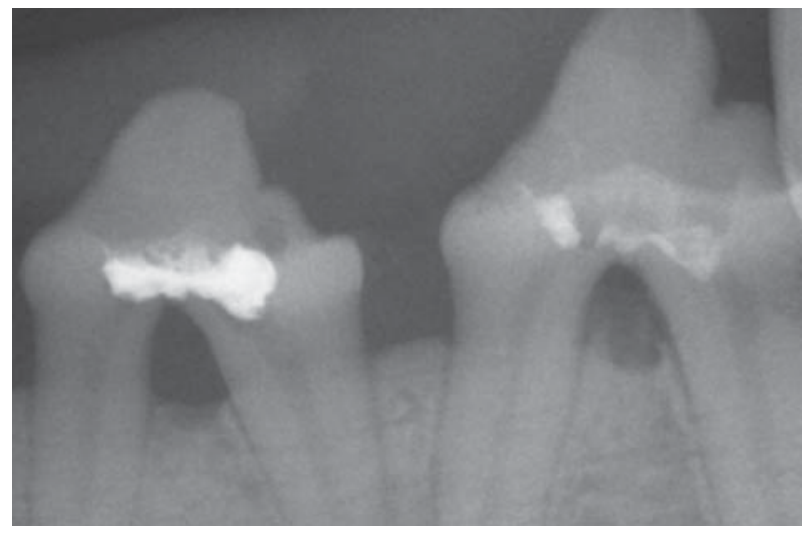

Figure 3- Periapical radiograph of the left mandibular second and third premolars sealed with gutta-percha and $\mathrm{AH}$ Plus, respectively, showing presence of periodontal lesion in the perforation region

\section{DISCUSSION}

During the coronal access phase of the endodontic treatment, perforation of pulp chamber floor in the furcation region might occur. Despite the advances in techniques and materials, management of root perforation repair remains a challenge. Factors such as the contamination of the area, time elapsed from the accidental perforation until the sealing of the communication, and the sealing ability of the repair material used to obliterate the defect will interfere with the prognosis of the case. Different materials have been used for perforation repair and several methodologies have been proposed to evaluate the behavior of these materials ${ }^{1-3,5-10,13,14,16,17,20}$.

This study compared the use of MTA, AH Plus, Vitremer and gutta-percha (control) for sealing mechanical root perforations in dogs' teeth on the basis of a radiographic evaluation within a 90day period. Yet, radiographic imaging is a widely employed diagnosis resource in clinical dental practice.

The canine experimental model used in the present investigation attempted to simulate situations that routinely occur under clinical conditions (i.e., masticatory activity, thermal cycling, oral microbiota, salivary flow variations). In addition, dogs present mineral structure and organic responses similar to those of humans and can withstand long periods of experimentation under anesthesia. These factors make dogs a commonly used model in previous studies ${ }^{1,4,8-11,14,16,20}$.

It is important to emphasize that prior to the clinical procedures the dogs were given atropine sulfate and were intubated. These conditions allowed the endodontic therapy to be conducted without absolute isolation because the tube avoided any interference of breathing and the administration of atropine inhibited salivary secretion.

Dogs' second and third premolars were selected for this study because of the anatomical characteristics of their pulp chamber and root canals. These teeth present two distinct roots (mesial and distal), which give them a well-defined pulp chamber floor. The fact that the second and third premolars allow the standardization of radiographic imaging was also considered while choosing the teeth to be used.

The LN bur used to create the communications between the pulp chambers and periapical tissues is commonly used to access root canals with posts. During this procedure, some deviation can occur and may cause a perforation. Also, it allowed standardizing the perforation size.

This study worked with dogs assigned to be used for UPF Medical School students, which were experimental animals of research protocol and would be sacrificed anyway. Otherwise, the experiment could have been carried out in vivo, with the animals alive.

The overall analysis of the findings of this study showed that none of the tested materials were capable of preventing the development of periodontal bone lesions in the furcation region. This might be attributed to the fact that the materials were not able to provide an impermeable sealing of the perforations and did not prevent the communication of the root canal system and oral fluids with the surrounding periodontal tissues.

The outcomes of the MTA group are consistent with those of previous studies $1,3,6,8,13,14,20$, which obtained promising results regarding MTA use for the repair of root perforation.

The treatment of root perforations remains unpredictable even in current days. Recent developments in the techniques and materials used to promote the repair of root perforations have enhanced the prognosis of both surgical and nonsurgical interventions. Further research is required to investigate the conditions of the ideal management as well as the characteristics of the 
materials available for this purpose.

\section{CONCLUSIONS}

According to the methodology proposed and based on the results of this study, it may be concluded that none of the tested materials (MTA, $\mathrm{AH}, \mathrm{GIC}$ and GP) was able to preserve the integrity of the periodontal tissues in the furcation region. Sealing of the perforations with MTA resulted in the least formation of adjacent periodontal bone lesions revealed by the radiographic comparisons.

\section{REFERENCES}

1- Al-Daafas A, Al-Nazhan S. Histological evaluation of contaminated furcal perforation in dogs' teeth repaired by MTA with or without internal matrix. Oral Surg Oral Med Oral Pathol Oral Radiol Endod. 2007;103:e92-9.

2- Alhadainy HA, Himel VT. Evaluation of the sealing ability of amalgam, Cavit and glass ionomer cement in the repair of furcation perforations. Oral Surg Oral Med Oral Pathol. 1993;75:362-6.

3- Arens DE, Torabinejad M. Repair of furcal perforations with mineral trioxide aggregate: two case reports. Oral Surg Oral Med Oral Pathol Oral Radiol Endod. 1996;82:84-8.

4- Bernabé PF, Holland R, Morandi R, Souza V, Nery MJ, Otoboni Filho JA, et al. Comparative study of MTA and other materials in retrofilling of pulpless dogs' teeth. Braz Dent J. 2005;16:149-55.

5- Dalat DM, Onal B. Apical leakage of a new glass ionomer root canal sealer. J Endod. 1998:24:161-3.

6- Daoudi MF, Saunders WP. In vitro evaluation of furcal perforation repair using mineral trioxide aggregate or resin modified glass ionomer cement with and without the use of the operating microscope. J Endod. 2002;28:512-5.

7- Ferris DM, Baumgartner JC. Perforation repair comparing two types of mineral trioxide aggregate. J Endod. 2004;30:422-4.

8- Ford TR, Torabinejad M, McKendry DJ, Hong CU, Kariyawasam $\mathrm{SP}$. Use of mineral trioxide aggregate for repair of furcal perforations. Oral Surg Oral Med Oral Pathol Oral Radiol Endod. 1995;79:756-63.
9- Holland R, Filho JA, Souza V, Nery MJ, Bernabé PF, Junior ED. Mineral trioxide aggregate repair of lateral root perforations. J Endod. 2001;27:281-4

10- Juárez Broon N, Bramante CM, Assis GF, Bortoluzzi EA, Bernardineli N, Moraes IG, et al. Healing of root perforations treated with Mineral Trioxide Aggregate (MTA) and Portland cement. J Appl Oral Sci. 2006;14:305-11.

11- Kopper PMP, Figueiredo JAP, Della Bona A, Vanni JR, Bier CA, Bopp S. Comparative in vivo analysis of the sealing ability of three endodontic sealers in post-prepared root canals. Int Endod J. 2003;36:857-63.

12- Lee SJ, Monsef M, Torabinejad M. Sealing ability of a mineral trioxide aggregate for repair of lateral root perforations. J Endod. 1993;19:541-4.

13- Nakata TT, Bae KS, Baumgartner JC. Perforations repair comparing MTA and amalgam using anaerobic bacterial leakage model. J Endod. 1998;24:184-6.

14- Noetzel J, Ozer K, Reisshauer BH, Anil A, Rössler R, Neumann $\mathrm{K}$, et al. Tissue responses to an experimental calcium phosphate cement and mineral trioxide aggregate as materials for furcation perforation repair: a histological study in dogs. Clin Oral Investig. 2006; 10:77-83.

15- Parirokh M, Torabinejad M. Mineral trioxide aggregate: a comprehensive literature review - Part III: clinical applications, drawbacks, and mechanism of action. J Endod. 2010;36:400-13. 16- Salman MA, Quinn F, Dermody J, Hussey D, Claffey N. Histological evaluation of repair using a bioresorbable membrane beneath a resin-modified glass ionomer after mechanical furcation perforation in dogs' teeth. J Endod. 1999;25:181-6.

17- Sluyk SR, Moon PC, Hartwell GR. Evaluation of setting properties and retention characteristics of MTA when used as furcation perforation repair material. J Endod .1998;24:768-71. 18- Torabinejad M, Chivian N. Clinical applications of mineral trioxide aggregate. J Endod. 1999;25:197-205.

19- Weine FS. Endodontic therapy. 6th ed. St. Louis: Mosby; 2004. 20- Yildirim T, Gençoğlu N, Firat I, Perk C, Guzel O. Histologic study of furcation perforations treated with MTA or Super EBA in dogs' teeth. Oral Surg Oral Med Oral Pathol Oral Radiol Endod. 2005;100:120-4. 